\title{
A Knowledge Database on Thermal Control in Manufacturing Processes* (Molding, Semiconductor Manufacturing, and Micro-Scale Manufacturing)
}

\author{
Shigeki HIRASAWA** and Isao SATOH***
}

\begin{abstract}
A prototype version of a knowledge database on thermal control in manufacturing processes, specifically, molding, semiconductor manufacturing, and micro-scale manufacturing has been developed. The knowledge database has search functions for technical data, evaluated benchmark data, academic papers, and patents. The database also displays trends and future roadmaps for research topics. It has quickcalculation functions for basic design. This paper summarizes present research topics and future research on thermal control in manufacturing engineering to collate the information to the knowledge database. In the molding process, the initial mold and melt temperatures are very important parameters. In addition, thermal control is related to many semiconductor processes, and the main parameter is temperature variation in wafers. Accurate in-situ temperature measurment of wafers is important. And many technologies are being developed to manufacture micro-structures. Accordingly, the knowledge database will help further advance these technologies.
\end{abstract}

Key Words: Optimal Control, Heat Transfer, Solidification, Thermal Radiation, Database, Manufacturing Process, Molding, Semiconductor Manufacturing, Micro-Scale Manufacturing

\section{Introduction}

The Japanese government's basic plan for science and technology in 2001 stated that manufacturing engineering was a major source of economic activity. Up to now, Japanese manufacturing technology has been mainly supported by skilled technicians, and they have accumulated much know-how. However, the number of skilled technicians is currently decreasing and this know-how might be lost. Globalization in the manufacturing field is another feature affecting the present Japanese industrial situation. Manufacturing technology should be advancing world-wide through the development of innovative technologies combined with information technology (IT). E-manufacturing $^{(1)}$ is one example of new manufacturing systems using Internet-based technologies. In addition, knowl-

* Received 16th April, 2003 (No. 03-4040)

** Mechanical Engineering Research Laboratory, Hitachi, Ltd., 502 Kandatsu, Tsuchiura, Ibaraki 3000013, Japan. E-mail : hira @merl.hitachi.co.jp

*** Department of Mechanical and Control Engineering, Tokyo Institute of Technology, 2-12-1 Ookayama, Meguro-ku, Tokyo 152-8552, Japan edge-database engineering is becoming increasingly important in manufacturing processes ${ }^{(2)}$.

In light of above circumstances, we began a research project to collate present information on thermal-control technologies in manufacturing processes to a knowledge database, which would be for common use on a public web site. As the first step, we are gathering as much data on thermal-control technologies as possible. Manufacturing engineering involves various widespread industrial fields. Valuable knowledge in one field is sometime different from that of another field. Thermal-control technologies therefore need to be summarized in a database and classified within their field and purposes. If people have studied technology in another field, they can obtain hints to make progress in their present field, which is a similar idea to the TRIZ (Theory of Inventive Problem Solving) algorithm ${ }^{(3)}$. Sharing benchmark data and clarifying the roadmaps for technologies are important in developing new technologies through industrial competition in a global society. It is true that many technologies for manufacturing processes are in the secret domain. However, for this research project, the sources for data are the public 
Table 1 Manufacturing research fields

\begin{tabular}{|l|c|c|}
\hline & $\begin{array}{l}\text { Japanese } \\
\text { conferences }\end{array}$ & $\begin{array}{l}\text { International } \\
\text { conferences }\end{array}$ \\
\hline Crystal growth & $52 \%$ & $20 \%$ \\
\hline $\begin{array}{l}\text { Semiconductor } \\
\text { manufacturing }\end{array}$ & $23 \%$ & $7 \%$ \\
\hline Molding & $3 \%$ & $4 \%$ \\
\hline Laser heating & $3 \%$ & $16 \%$ \\
\hline Welding & $6 \%$ & $4 \%$ \\
\hline Casting & $3 \%$ & $15 \%$ \\
\hline Coating & $3 \%$ & $4 \%$ \\
\hline Cutting & & $4 \%$ \\
\hline Furnace heating & & $7 \%$ \\
\hline Particles & & $7 \%$ \\
\hline Fibers, and glass & & $8 \%$ \\
\hline Others & $7 \%$ & $4 \%$ \\
\hline
\end{tabular}

domain, such as published papers, patents or Internet web sites. Occasionally, actual temperature data cannot be measured due to various restrictions, so non-thermal data, such as changes in electrical performance, is used as a parameter for industrial manufacturing processes. The relation between non-thermal data and process conditions therefore also need to be stored in the database. Thermal control is only one technology and many other technologies are necessary in manufacturing engineering. Optimum conditions are considered to be a good balance of several parameters, such as performance, cost, and size. It is therefore necessary to provide not only data on the optimum conditions for special cases but also access to basic data on the effects of changing parameters in manufacturing processes.

Table 1 lists a breakdown of the fields concerning recent manufacturing research presented at heat transfer sessions of Japanese and international conferences. The Japanese conferences include the 2001 and 2002 JSME Thermal Engineering Conferences and the 2002 National Heat Transfer Symposium of Japan. International conferences include the 2002 ASME International Mechanical Engineering Conference and the 2002 International Heat Transfer Conference. About $70 \%$ of recent Japanese research has been done on crystal growth and semiconductor manufacturing. However, international research has a broader range in varied fields. Japanese research is only covering part of what industries in various fields require; therefore, collecting a wide range of information for storage in a database and making the database are key tasks for Japanese industries.

To meet the above requirements, the authors have established a prototype version of a knowledge database for thermal control in manufacturing pro- cesses, specifically, molding, semiconductor manufacturing, and micro-scale manufacturing.

\section{A Knowledge Database on a Web Site}

Knowledge databases can be used for various purposes by a wide range of users. Developing a knowledge database on thermal control in manufacturing processes would bring three main advantages.

(1) A search function for technical data, academic papers, patents, commercial simulation programs, and present research activities.

(2) Quick calculation functions for basic design.

(3) A window for consultation on new problems.

Evaluated benchmark data would also be available from the database. A comparison of experimental data and calculation results from different institutes would also be available, and the database would display trends and future roadmaps for research topics. The quick calculation functions use equations in publicly accessible papers. Numerical simulation on a web server computer would be possible. The window for consultation would be useful in gathering new information on industrial needs and improving the database.

As an example of databases on web sites, Fig. 1 shows a welding database developed by the National Institute for Materials Science through the support of the Japan Science and Technology Corporation ${ }^{(4)}$. It can be used for predicting the micro-structures and mechanical properties of weld heat-affected zones. It combines a database containing continuous-cooling transformation diagrams for welding (CCT diagrams) and a system for computing weld thermal histories. The target is to develop a distributed database system, using XML (Extensible Markup Language), called "Data-Free-Way" in which each database is operated by a different organization. Other distributed network databases of thermal properties have been developed ${ }^{(5)}$.

Figure 2 shows the contents and calculation-function pages of the prototype version of a knowledge database on thermal control in manufacturing processes that we are developing. Figure 3 shows the system of the knowledge database. The web address for this prototype database is:

http://netsu-n.mep.titech.ac.jp/SATOH/AJ_ KN3/databe.html.

Figure 4 shows the design flow for determining optimum thermal-control conditions. The data in the prototype database is arranged along this design flow. A large amount of data will be gathered prior to constructing a practical version of the database. The prototype database covers research topics on thermal control in molding, semiconductor manufacturing, and 


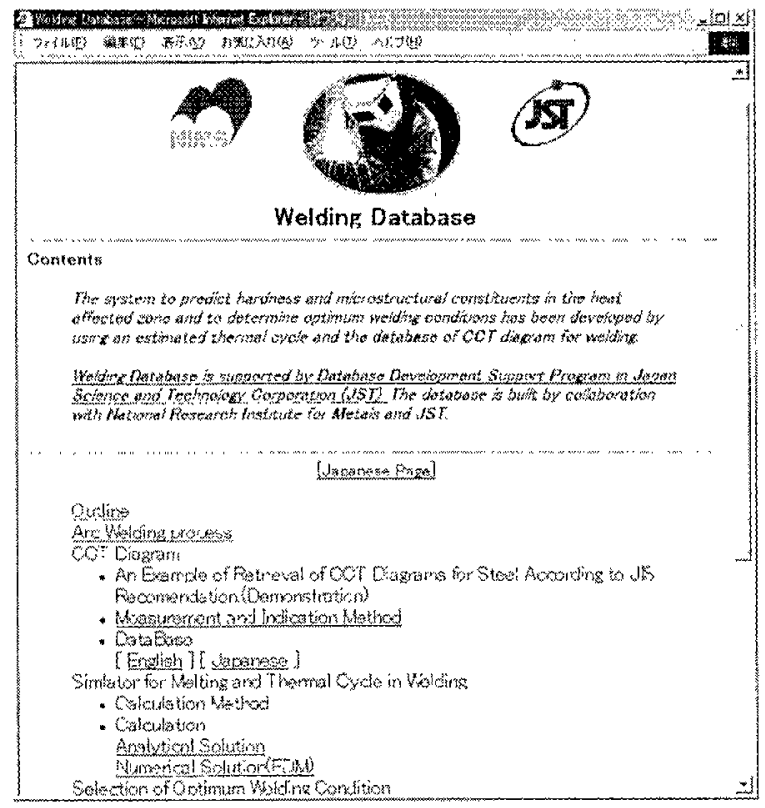

(a) Contents page

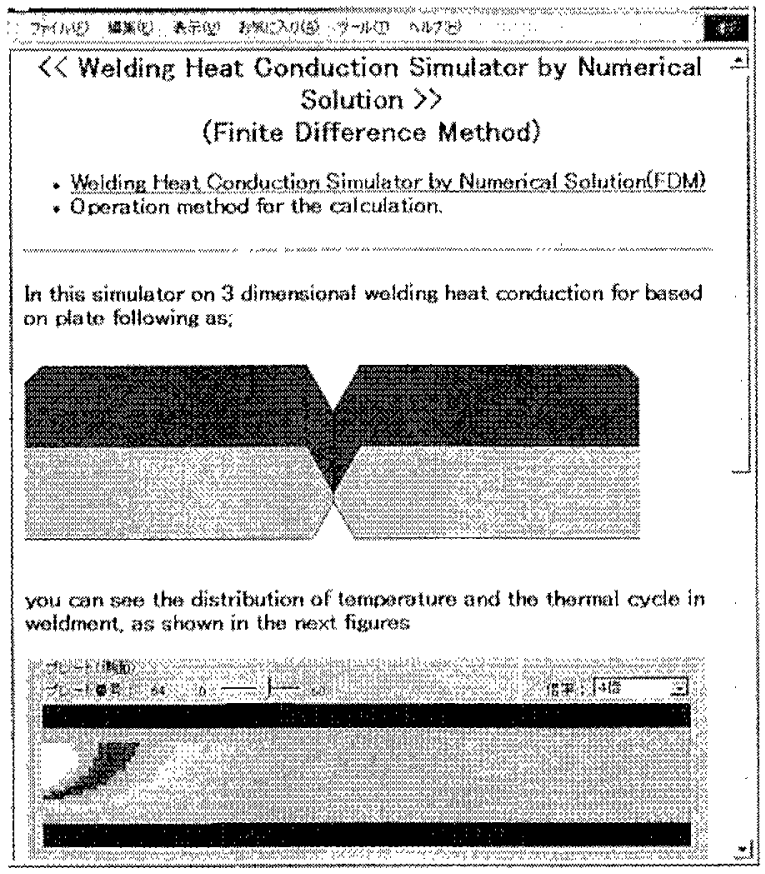

(b) Calculation of temperature distribution

Fig. 1 Database for welding conditions ${ }^{(4)}$

micro-scale manufacturing processes.

\section{Molding Processing}

\section{1 Thermal control during molding}

Injection-molding technology was developed around 1935, and the application of polymers to industrial products is a representative technology of the 20 th century. The molding process is indispensable in the manufacture of compact disks (CDs) or digital versatile disks (DVDs), which are examples of appli-

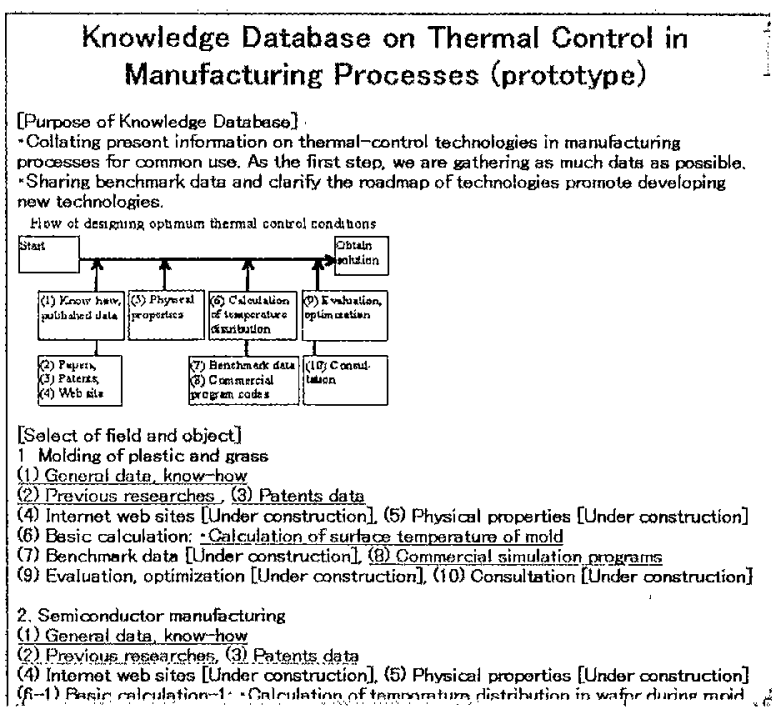

(a) Contents page

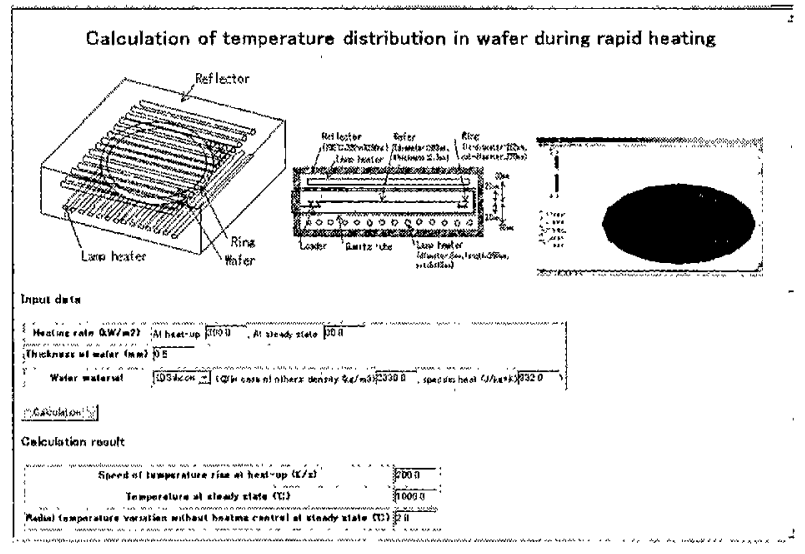

(b) Function to quickly calculate temperature distribution in a wafer during rapid heating

Fig. 2 Prototype version of knowledge database of thermal control in manufacturing process

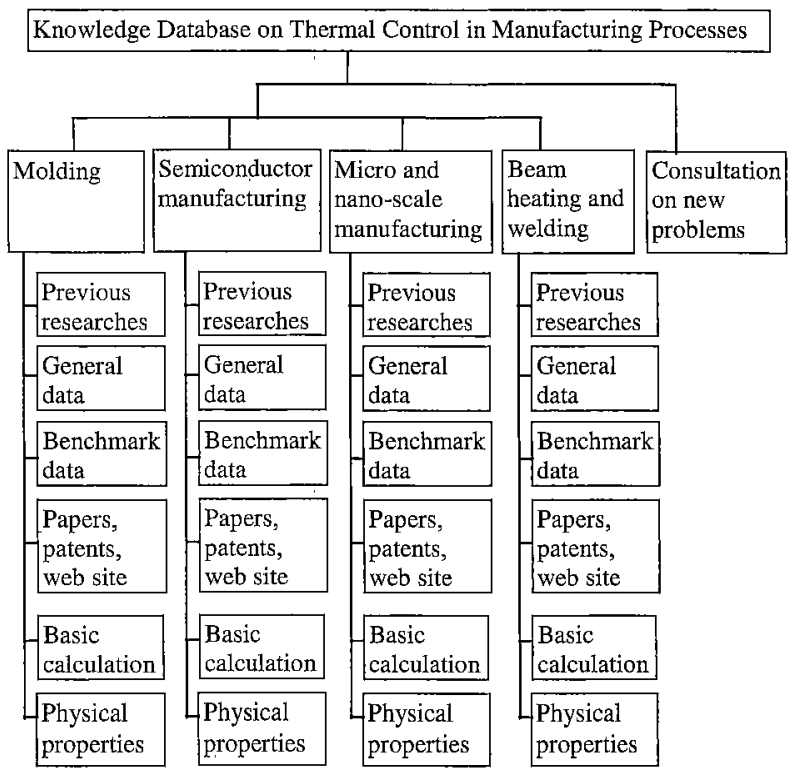

Fig. 3 System of knowledge database 


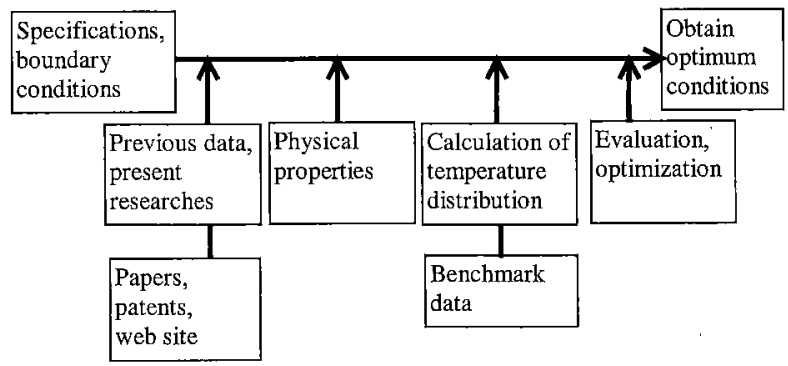

Fig. 4 Design flow of optimum thermal-control conditions

cation of micro and nano-scale technologies applied to mass-produced commodities. Thermal control during the molding process is extremely important. The polymer molding process involves melting a polymer, injecting the molten material into a mold, cooling it, then separating it from the mold. Table 2 lists the relations between defects in the molding process and thermal parameters. Information on optimizing the conditions for thermal control is gathered and stored in a knowledge database.

\section{2 Research on thermal control}

Table 3 shows a map of the research subjects, placed in their representative scale order, described in this paper. During the injection process, the surface of the molten polymer starts to freeze as soon as it contacts the cold wall of the mold. Precise local temperature control of the polymer surface during the process by using laser heating has been developed. Figure 5 plots the effect of laser power on the ability to replicate grooved patterns $8 \mu \mathrm{m}$ in depth and $10 \mu \mathrm{m}$ in width ${ }^{(6)}$. It is clear that transcription (i.e., higher replication ratio) is better when the melt has a higher initial surface temperature. However, if the initial surface temperature of the melt and the mold are too high, the polymer surface may stick to the mold surface, and the product is seriously deformed on separation. Figure 6 shows the effect of initial mold temperature on the maximum separation stress for press-molded glassware ${ }^{(7)}$. At present, optimal initial temperatures for the melt and mold cannot be calculated numerically and are determined from experimental data. This experimental data is currently being transferred to the knowledge database.

Figure 7 shows the wavy flow marks that characterize surface defects created during injection molding(8). The mechanism producing the flow marks can be explained as a heat and fluid phenomenon, which is based on the non-uniform thermal contraction of the polymer in the solidifying layer closely behind the contact line. To prevent flow marks from forming, the surface temperature of the mold and flow velocity of the melt must be optimally controlled. This can be
Table 2 Relation between defects in molding process and thermal parameters

\begin{tabular}{|l|l|}
\hline Defects & Thermal parameters \\
\hline Flow-mark & $\begin{array}{l}\text { Surface temp. of mold and melt } \\
\text { at filling }\end{array}$ \\
\hline Non-transcription & $\begin{array}{l}\text { Surface temp. of mold and melt } \\
\text { at cooling }\end{array}$ \\
\hline Broken at separation & $\begin{array}{l}\text { Surface temp. of mold at } \\
\text { separation }\end{array}$ \\
\hline $\begin{array}{l}\text { Residual stress, deformation, } \\
\text { and sink-marks }\end{array}$ & $\begin{array}{l}\text { Temp. distribution in mold, and } \\
\text { non-uniform cooling }\end{array}$ \\
\hline Voids in products & $\begin{array}{l}\text { Heating temp. of melt, heating } \\
\text { time, and cooling speed }\end{array}$ \\
\hline
\end{tabular}

Table 3 Research subjects in molding process

\begin{tabular}{|c|c|c|c|c|}
\hline Size & $\mathrm{mm}$ & & $\mu \mathrm{m}$ & $\mathrm{nm}$ \\
\hline \multirow{2}{*}{ Subjects } & $\begin{array}{l}\text { Macro } \\
\text { transcription, } \\
\text { separation }\end{array}$ & Flow-mark & {$\left[\begin{array}{l}\text { Micro } \\
\text { transcription } \\
\text { (CDs, DVDs) }\end{array}\right.$} & \multirow{2}{*}{$\begin{array}{l}\text { Surface } \\
\text { roughness } \\
\text { (optical } \\
\text { waveguides) }\end{array}$} \\
\hline & $\begin{array}{l}\text { Residual } \\
\text { stress }\end{array}$ & & $\begin{array}{l}\text { Active micro } \\
\text { temperature } \\
\text { control }\end{array}$ & \\
\hline
\end{tabular}

Surface temperature of melt

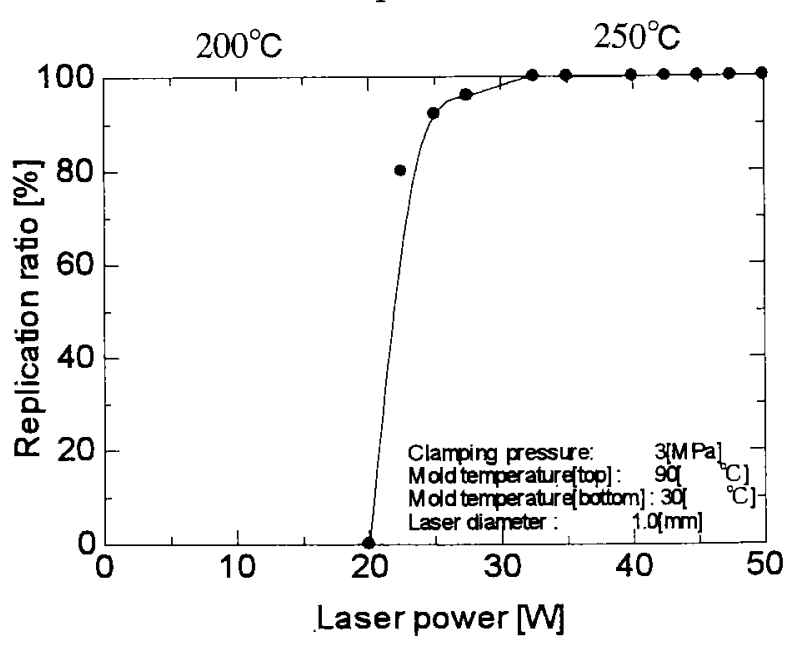

Fig. 5 Effect of laser power on replication ability ${ }^{(6)}$

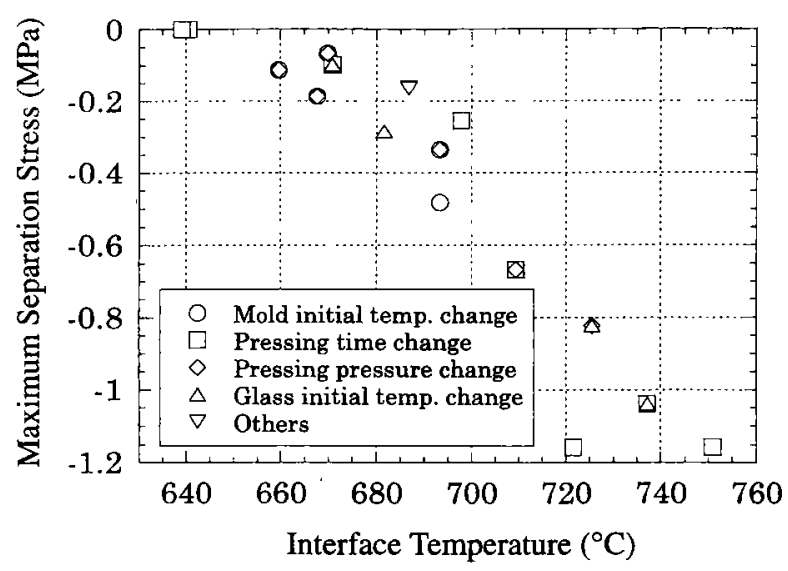

Fig. 6 Effect of initial mold temperature on maximum separation stress $^{(7)}$ 
calculated numerically for specific polymer and mold conditions.

Functional surfaces can be manufactured when the local temperature distribution of the material can be controlled at will. Active micro-temperature-control technology is important for developing next generation of the new products ${ }^{(9)}$.

Molding is particularly important in applying

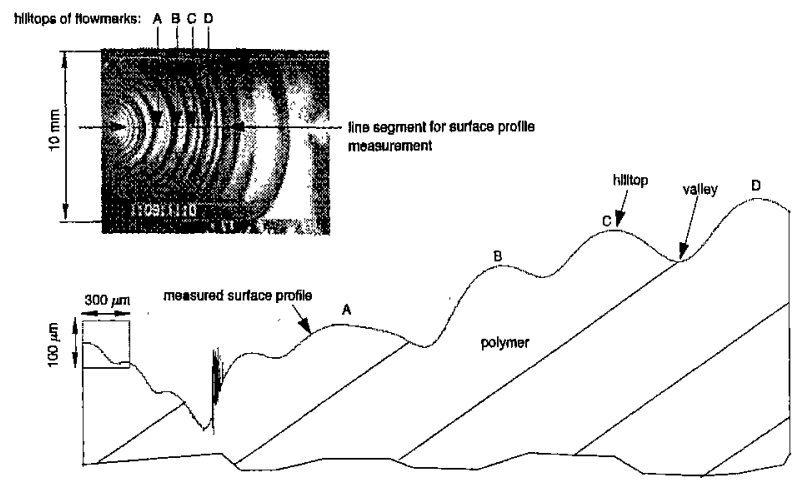

(a) Flow marks

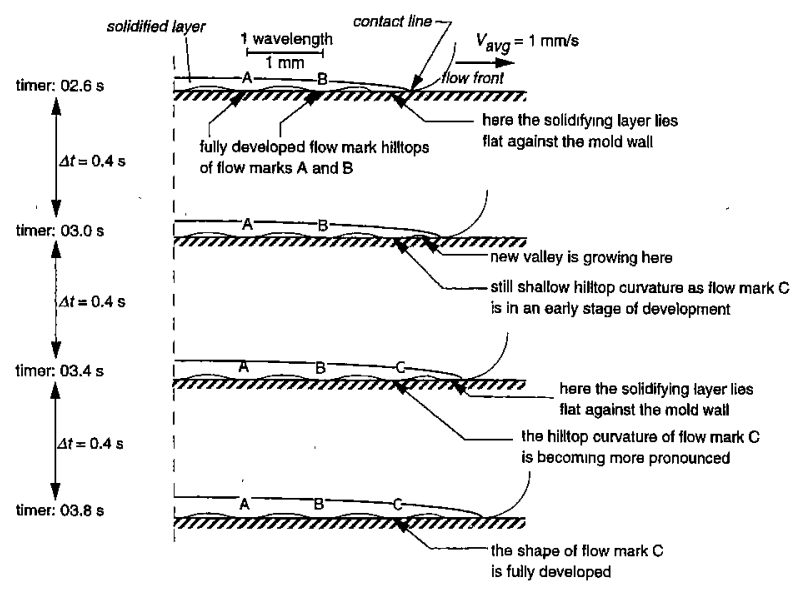

(b) Mechanism for flow marks

Fig. 7 Flow-mark defects in injection-molding process ${ }^{(8)}$

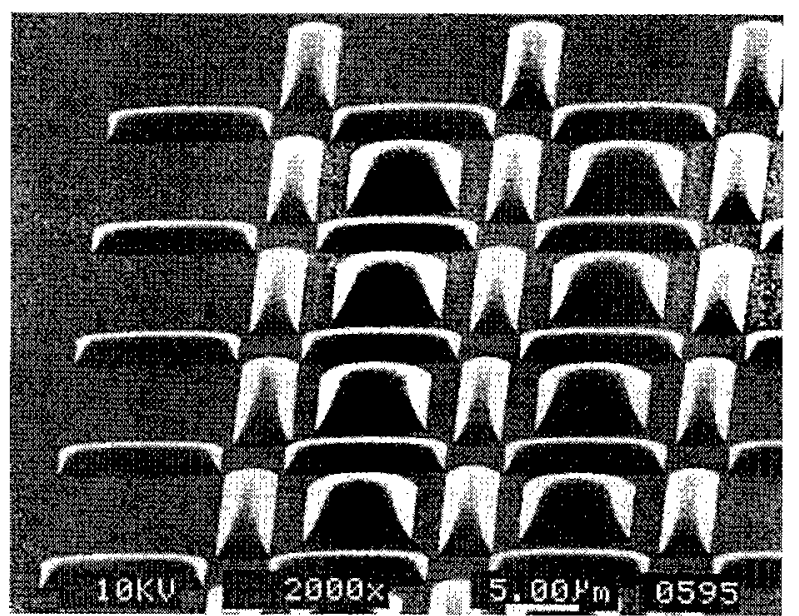

Fig. 8 Surface geometry of $\mathrm{CD}^{(10)}$ micro and nano-scale technologies. The manufacturing of micro-surface geometry on CDs or DVDs is an example. Figure 8 shows the surface geometry of a $\mathrm{CD}^{(10)}$. The present depth of the surface geometry of a CD is $100 \mathrm{~nm}$ and the lateral width is $400 \mathrm{~nm}$. The future target for the aspect ratio (depth to width) is expected to be greater than one. As another example of nano-scale technologies, molding technology for polymer optical waveguides has been developed ${ }^{(11)}$. A polymer optical waveguide is composed of a core surrounded by cladding, and mounted on a substrate. The core and the cladding are made of various plastic materials. The present target for the width of the core is several hundred nano-meter and the surface roughness should be less than several nano-meter.

\section{3 . 3 Thermal properties, simulation programs, and patents}

Predicting the thermal properties of polymers is important. For example, to model the conductivity anisotropy in linear-chain polymer films, theoretical research of heat conduction in stretched bulk polymers has been reported ${ }^{(12)}$. This data on thermal properties, and ways to predict them, will be stored in the knowledge database. And commercial simulation programs for optimizing molding processes have been developed ${ }^{(13),(14)}$. And their web addresses are included in the knowledge database so that they can be consulted.

Patents provide a good source of practical information on manufacturing technologies. Patents, related to the thermal control of molding processes, were searched using the key words "plastic", "molding", and "heat" in Japanese patents opened to the public in 2001 and 2002. Five patents were found and most of them are related to the mixing ratio of several polymers. As basic patents related to thermal control may have been taken out many years ago, old-patent information is going to be included in the database.

\section{Semiconductor Manufacturing Processes}

\section{1 Thermal control in semiconductor manufac- turing processes}

Integrated circuits (ICs) were developed around 1960, and the electronics industry led the way in their use towards the latter part of the 20 th century. Semiconductor manufacturing is composed of many processes, such as crystal growth, lithography, ion implantation, etching, film deposition, epitaxy, oxidation, diffusion, annealing, metallization, and reflow. Thermal control is necessary for many of these processes, and Table 4 lists the purpose of thermal control, the thermal parameters, and the process temperatures and variations in the semiconductor manufacturing process. The main parameter is tempera- 
Table 4 Relation between semiconductor manufacturing process and thermal parameters

\begin{tabular}{|l|l|l|l|}
\hline Process & $\begin{array}{l}\text { Purpose of thermal } \\
\text { control }\end{array}$ & $\begin{array}{l}\text { Thermal } \\
\text { parameters }\end{array}$ & $\begin{array}{l}\text { Process temp. } \\
\text { and variations }\end{array}$ \\
\hline Crystal growth & $\begin{array}{l}\text { Uniform crystal growth, } \\
\text { prevent defects }\end{array}$ & $\begin{array}{l}\text { Temperature } \\
\text { control }\end{array}$ & $\begin{array}{l}1700 \mathrm{~K} \\
\pm 10 \mathrm{~K}\end{array}$ \\
\hline Lithography & Accurate resolution & $\begin{array}{l}\text { Constant } \\
\text { temperature }\end{array}$ & $\begin{array}{l}300 \mathrm{~K} \\
\pm 0.02 \mathrm{~K}\end{array}$ \\
\hline $\begin{array}{l}\text { Film } \\
\text { deposition }\end{array}$ & $\begin{array}{l}\text { Uniform film deposition, } \\
\text { prevent defects }\end{array}$ & $\begin{array}{l}\text { Uniform } \\
\text { ternperature }\end{array}$ & $\begin{array}{l}1300 \mathrm{~K} \\
\pm 0.5 \mathrm{~K}\end{array}$ \\
\hline $\begin{array}{l}\text { Oxidation, } \\
\text { diffusion, and } \\
\text { annealing }\end{array}$ & $\begin{array}{l}\text { Uniform heating and } \\
\text { cooling, prevent thermal } \\
\text { stress }\end{array}$ & $\begin{array}{l}\text { Uniform } \\
\text { temperature }\end{array}$ & $\begin{array}{l}1300 \mathrm{~K} \\
\pm 1 \mathrm{~K}\end{array}$ \\
\hline Metalization & $\begin{array}{l}\text { Prevent defects at low } \\
\text { temperature }\end{array}$ & $\begin{array}{l}\text { Temperature } \\
\text { control }\end{array}$ & $\begin{array}{l}700 \mathrm{~K} \\
\pm 1 \mathrm{~K}\end{array}$ \\
\hline
\end{tabular}

ture distribution. The present size of the surface pattern is already at the nm scale (minimum size along the surface is $115 \mathrm{~nm}$ and minimum film thickness is $1.2 \mathrm{~nm}$ in 2002), and this scale is still being reduced by about $85 \%$ each year ${ }^{(15)}$. Information on the technology to optimize thermal control conditions is being collected and stored in the knowledge database. The manufacturing processes for MEMS technologies is based on the semiconductor manufacturing processes so a knowledge database is also useful for these technologies.

\section{2 Research on thermal control of heating process}

Table 5 shows the relationship between the minimum size of the surface pattern and research processing parameters on oxidation, diffusion, and annealing processes. In order to reduce cost of mass production of LSIs, uniform heating technology is important in semiconductor manufacturing processes. Technology to produce uniform heating for about 10 minutes, in a batch-type furnace, was developed in the 1990 s and various innovations that reduce temperature distribution have been reported ${ }^{(16)}$.

Technology that produces uniform heating for about one minute using a lamp heating apparatus was developed in the 2000s. Figure 9 ( a ) shows a vertical cross-section of a rapid-thermal-processing (RTP) apparatus that uses lamp heaters. Figure 9 (b) shows the effect of the monitoring location and the number of lamps on temperature variations during heat $\mathbf{u p}^{(17)}$. Minimum temperature variations in the wafer of \pm 0.1 $\mathrm{K}$ at $1273 \mathrm{~K}$ are possible when heating is optimally controlled. However, the accuracy in measuring the in-situ temperature of the wafer is $\pm 1 \mathrm{~K}$ and causes a bottleneck in controlling the heating rate. Figure 10 shows the effect of the natural convection of gas on temperature variations in a wafer at $1273 \mathrm{~K}^{(18)}$. Temperature variations increase by $1.4 \mathrm{~K}$ because of the effect of the natural convection of gas. The effect of convection can be minimized by rotating the wafer and controlling the heating rates of lamps.
Table 5 Research subjects in semiconductor heating process

\begin{tabular}{|l|l|l|l|}
\hline $\begin{array}{l}\text { Minimum } \\
\text { pattern size }\end{array}$ & $1 \mu \mathrm{m}$ & $100 \mathrm{~nm}$ & $10 \mathrm{~nm}$ \\
\hline Heating time & $10 \mathrm{~min}$ & $1 \mathrm{~min}$ & $1 \mathrm{sec}$ \\
\hline Heater type & Furnace & Lamp & $\begin{array}{l}\text { Laser, } \\
\text { plasma assist }\end{array}$ \\
\hline $\begin{array}{l}\text { Thermal } \\
\text { parameters }\end{array}$ & $\begin{array}{l}\text { Control of } \\
\text { bulk } \\
\text { temperature }\end{array}$ & $\begin{array}{l}\text { Control of } \\
\text { local } \\
\text { temperature }\end{array}$ & $\begin{array}{l}\text { Control of } \\
\text { micro surface } \\
\text { temperature }\end{array}$ \\
\hline
\end{tabular}

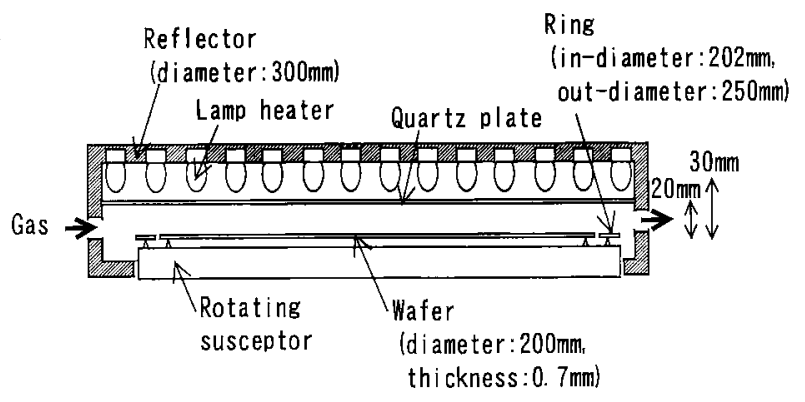

(a) Vertical cross-section of lamp-heating apparatus

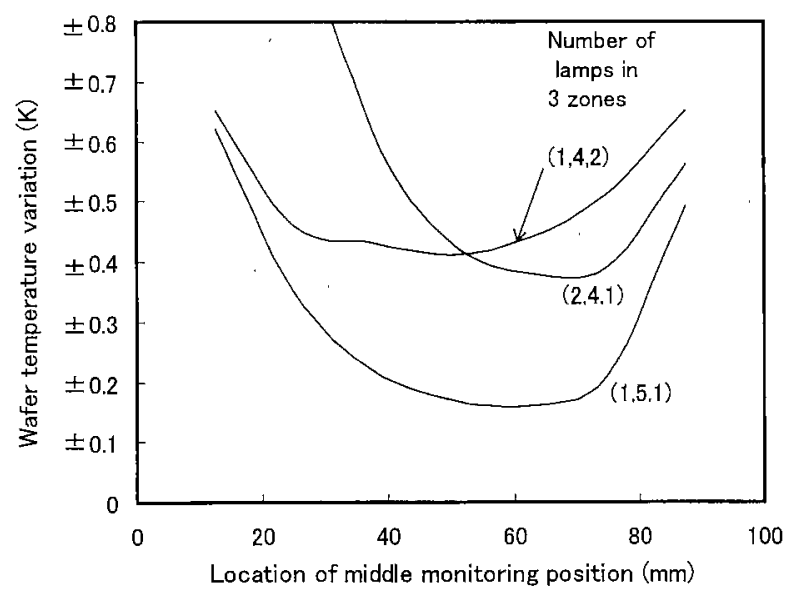

(b) Effect of location of monitoring position and number of lamps on temperature variations

Fig. 9 Lamp-heating apparatus ${ }^{(17)}$

In future semiconductor heating processes, innovations in higher and lower temperature processes are required ${ }^{(19)}$. Higher-temperature heating processes up to $1673 \mathrm{~K}$, near the silicon melting point, will be necessary to produce oxide film for silicon-on-insulator (SOI) and trench-isolation structures. Presently however, such high-temperature heating processes are difficult because thermal stress causes defects in wafers. Uniform temperatures are very important, especially because silicon yield strength is low at high temperatures. On the other hand, lower temperature heating processes at less than $723 \mathrm{~K}$ and very short heating processes of less than one second will be necessary to produce thin oxide films and shallow junctions without thermal effects compromising other 


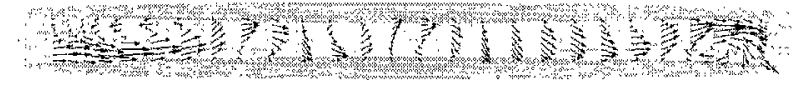

(a) Velocity distribution in center vertical cross section

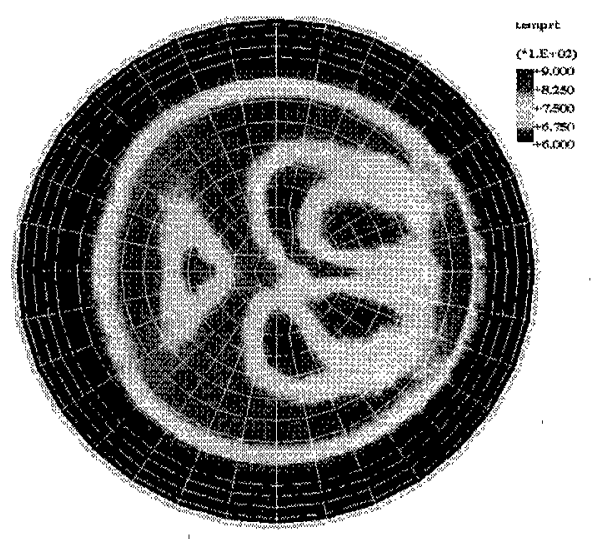

(b) Temperature distribution $5 \mathrm{~mm}$ above wafer

Fig. 10 Velocity and temperature distributions in $\operatorname{gas}^{(18)}$

areas of the devices. At lower temperatures, the production rate is very low and new plasma assisted processing technologies such as atomic-layer deposition $(A L D)^{(20)}$ need to be developed. New heating technologies are also being developed to achieve rapid heating by lasers or flash-lamp heaters. However, rapid heating is difficult because local thermal stress causes defects in wafers. It is also difficult to develop a system to measure and control the wafer temperature under rapid heating conditions. The characteristics of the wafer (e.g., thickness and surface pattern) vary by several percent in an actual semiconductor manufacturing processes, so thermal control should be changed according to individual conditions. Our knowledge database on thermal control is very important in developing new control systems.

Thermal control is one of the key technologies in semiconductor manufacturing process, but there are other tremendous challenges such as the development of new materials, reliability, process integration, and plasma process control that must also be faced. A knowledge database on thermal control would help researchers in these various fields of semiconductor manufacturing process.

\subsection{Thermal properties, simulation programs, and patents}

Data on the thermal radiation properties of micro patterns on a silicon wafer is important for radiation heating. The reflectance of a micro patterned surface has thus been measured ${ }^{(21)}$. Moreover, the surface film thickness changes during the heating process. And the thermal radiation properties of silicon wafers with various surface-film thickness have been reported. Data on thermal properties and ways of predicting the properties of various materials are being gathered and stored in the knowledge database. Commercial simulation programs have been developed for crystal growth, etching, film deposition, epitaxy, oxidation, diffusion, annealing, and metallization ${ }^{(13),(22)}$.

Patents related to the thermal control of semiconductor manufacturing processes were searched for by using the key words "semiconductor manufacturing" and "thermal control" in Japanese patents opened to the public in 2001 and 2002 . Seven patents were found and they concerned areas such as improvements to apparatus and new heating processes. As the basic patents related to thermal control may have been taken out years ago, it is necessary to store such oldpatent information in the database.

\section{4 Quick calculation function on web}

At the initial stages of optimizing a process design, basic calculations involving changing parameters are very important. A quick calculation is important in the basic design. There have been some innovative methods to increase computation speed without decreasing accuracy. One such method is the built-up approach ${ }^{(23)}$, which uses compressed solutions. Another uses a model of the final target conditions to reduce the number of computation elements $^{(24)}$. The basic calculation function of temperature variation in wafer during rapid heating is given in a web-browser window (Fig. 2(b)). After inputting the data (i.e., thermal properties of materials) and clicking on the calculation button, the temperature variation in the wafer is quickly calculated.

\section{Micro Scale Manufacturing Processes}

\section{1 Thermal control in micro and nano-scale manufacturing processes}

The scanning tunneling microscope (STM) was developed around 1980, and micro and nano-scale technologies are currently its leading research topics. The manufacturing processes for micro and nanoscale technologies are similar to semiconductor manufacturing processes, but there are some differences. The manufacture of micro and nano-scale devices involves various materials and geometries and requires special technology. A large number of manufacturing technologies are being developed, and there is a lot of new trial data. Therefore, although it may be a little too early to gather data for a knowledge database on thermal control, we have started to collect it.

\section{2 Research on thermal control}

For thermal control in a micro-scale manufacturing process using a $\mathrm{CO}_{2}$ laser, the surface micro profile of a glass plate can be controlled by changing the heating time. Various profiles can be obtained by 


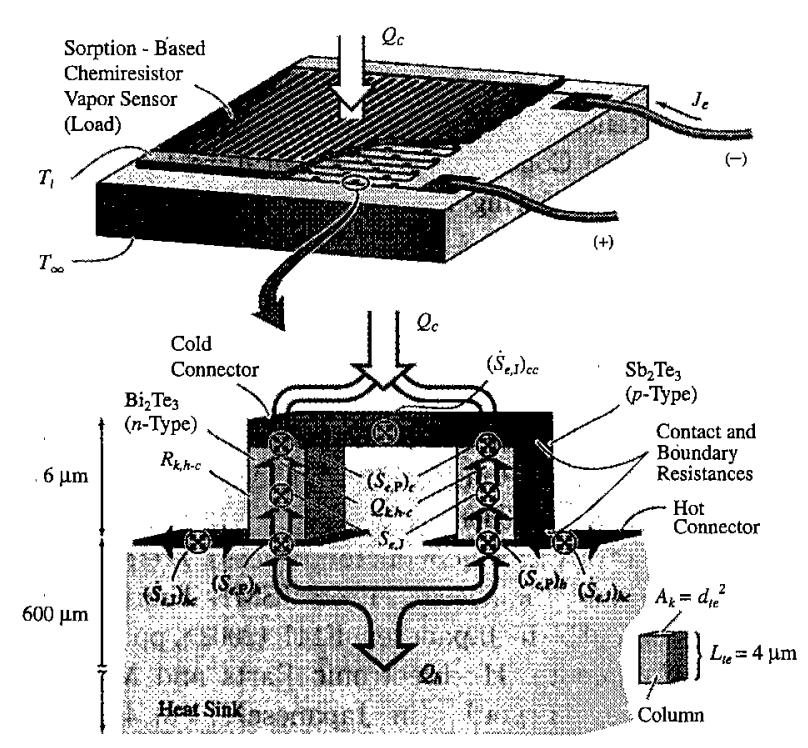

Fig. 11 Micro thermoelectric cooler ${ }^{(28)}$

changing the heating conditions ${ }^{(25)}$. Such data on the effects of heating conditions can be transferred to the knowledge database. Laser micro-fabrication technology can be used to machine structures $100 \mathrm{~nm}$ in size. Coupled with atomic force microscopy (AFM), it can achieve a resolution of $10 \mathrm{~nm}^{(26)}$. Chemical etching rates are greatly dependent on temperature; therefore, fabricating micro-structures on silicon substrates is possible by changing the local temperature of the substrate with a heater ${ }^{(27)}$.

Figure 11 shows a micro thermoelectric cooler ${ }^{(28)}$, which is a promising device for accurate control of local temperature. There are 50 pairs of $7 \mu \mathrm{m}^{-}$wide columns on a substrate. The columns are manufactured by vapor deposition. To produce a micro thermoelectric cooler, the manufacture of columns with uniform lengths and uniform alloy concentrations is very important. A special manufacturing process has been devised, and knowledge data on an optimal manufacturing process are being accumulated.

\section{3 Patents information}

Patents related to the thermal control of nanoscale manufacturing processes were found by searching by the key words "nano", "manufacturing", and "heat" in the Japanese patents opened to the public in 2001 and 2002. Since nano technology is going to be practical in the near future, more than 50 patents were found. Table 6 lists the number of patents for thermal control of nano-scale manufacturing under various classifications. There are many patents on mass products and ways of controlling the shape of the nano-tubes. Information on thermal control devices for this technology is being included in the knowledge database.
Table 6 Number of patents for thermal control of nano-scale manufacturing

\begin{tabular}{|l|l|c|l|c|}
\hline & $\begin{array}{l}\text { Mass } \\
\text { products, } \\
\text { efficiency }\end{array}$ & Shape control & $\begin{array}{l}\text { Specific } \\
\text { process } \\
\text { conditions }\end{array}$ & Total \\
\hline Powder & 2 & 2 & 1 & 5 \\
\hline Thin film & 1 & 3 & & 4 \\
\hline Crystal & 1 & 2 & 2 & 5 \\
\hline Nano-tubes & 14 & 11 & 3 & 28 \\
\hline Coils, and fibers & 6 & & & 6 \\
\hline Manufacturing & 5 & 4 & 1 & 10 \\
\hline Total & 29 & 22 & 7 & \\
\hline
\end{tabular}

\section{4 Future research topics}

The research scope and various topics on nanomanufacturing are summarized in Ref.(29). The effects of the wall and the thermal conduction are large in micro-scale manufacturing and are effective for rapid cooling. The potential for developing breakthrough technologies in micro-scale manufacturing is quite high. Examples of break-through technologies are self-assembly during a micro-manufacturing process, extreme uniformity of $0.001 \mathrm{~K}$ by means of laser-heating control, and an accurate method for measuring temperature on the micro-scale. The knowledge database will make a significant contribution to realizing these break-through technologies.

\section{Summary}

A knowledge database on thermal control in manufacturing processes, specifically molding, semiconductor manufacturing, and micro-scale manufacturing processes, is being developed. In the knowledge database, data on research results, data on patents, and future research subjects can be searched. It has quick-calculation functions for basic design. A prototype version of the knowledge database is displayed at the following web address:

http://netsu-n.mep.titech.ac.jp/SATOH/AJ_

$\mathrm{KN} 3 /$ databe.html.

A practical version of the database will be developed in 2003 and 2004 . We hope that our database will be used by as many researchers as possible and would be grateful for their comments on its effectiveness. We would also welcome any data that could be included in the database.

\section{Acknowledgements}

The authors would like to thank Dr. Mitsutane Fujita of the National Institute for Materials Science, Japan, for helpful suggestions on a database system.

\section{References}

(1) Waurzyniak, P., Moving Toward the e-Factory, SME Manufacturing Magazine, Vol. 127, No. 5 (2001), http://www.sme.org/gmn/mag/2001/ 01nom042/01nom042.pdf 
(2) Crabb, H.C., Virtual Engineering, Soc. Manufacturing Engineers and ASME, (1998), p. 85

(3) TRIZ Home Page in Japan, http://www.osaka gu.ac.jp/php/nakagawa/TRIZ/e'TRIZ/

(4) Kasugai, T. and Fujita, M., Atlas of CCT Diagrams for Welding ( I ), National Research Institute for Metals Special Report No.99-02

(5) Baba, T. and Ono, A., Development of Network Database of Thermophysical, Proc. JSME Thermal Eng. Conf. '02, (in Japanese), D216 (2002), pp. $415-416$

(6) Sato, K., Ohashi, T., Saito, T. and Kurosaki, Y., Development of the Moldability Improvement of Precise Plastic Articles by Improving the Efficiency of Heat Transfer, Proc. JSME Thermal Eng. Conf. '02, (in Japanese), D221 (2002), pp. 417-418.

(7) Wakatsuki, H. and Satoh, I., Study on Separation Behavior of a Press-Molded Glassware from a Thermal Engineering Viewpoint, Proc. 6th ASME-JSME Thermal Eng. Joint Conf., TEDAJ03-153 (2003).

(8) Tredoux, L., Satoh, I. and Kurosaki, Y., Investigation of Wave-like Flow Marks in Injection Molding, Polymer Engineering \& Science, Vol. 40, No. 10 (2000), pp. 2161-2174.

(9) Saito, T., Satoh, I. and Kurosaki, Y., An Application of $\mathrm{CO}_{2}$ Laser Interference Heating for Polymer Injection Molding Process, Proc. 5th ASMEJSME Thermal Eng. Joint Conf., AJTE99-6468 (1999)

(10) Schif, H., David, C., Gobrecht, J., Amore, A.D., Simoneta, D., Kaiser, W. and Gabriel, M., Quantitative Analysis of the Molding of Nanostructures, J. Vac. Sci. Technol. B, Vol. 18, No.6 (2000), pp. 3564-3568.

(11) NTT Advanced Co., http://www.keytech.ntt-at. co.jp/optic2/prd_e0015.htm1

(12) Kurabayashi, K. and Goodson, K.E., Impact of Molecular Orientation on Thermal Conduction in Linear-Chain Polymer Films, Proc. 5th ASMEJSME Thermal Eng. Joint Conf., AJTE99-6215 (1999).

(13) Concentration, Heat \& Momentum Ltd., http:// www.cham.co.uk/

(14) ESI Group, http://www.esi-group.com

(15) International Technology Roadmap for Semiconductors (2001 Ed.), http://public.itrs.net

(16) Mochida, A., Kudo, K., Hishinuma, Y. and Miyata, T., Effects of Rings on Leveling the Temperature Distribution of Wafers in Quick Heat up Process, 39th National Heat Transfer Symp. of Japan '02, (in Japanese), G211 (2002), pp. $513-514$.

(17) Hirasawa, S., Suzuki, T., Maruyama, S. and Takeuchi, Y., Analysis of the Effect of Heating Control Conditions on Temperature Variation in a Wafer during Rapid Thermal Processing with Lamp Heaters, Proc. ASME Int. Mech. Eng. Cong., HTD-Vol. 369-6, IMECE2001/HTD-24334 (2001), pp. 37-44.

(18) Hirasawa, S. and Maruyama, S., Analysis of Gas Convection and Temperature Distribution in a Rotating Wafer in a Cylindrical Lamp Heating Apparatus, Proc. ASME Int. Mech. Eng. Cong., IMECE2002-33087 (2002).

(19) Mukai, K., Semiconductor Process Trend and Its Thermo-Engineering, Proc. JSME Thermal Eng. Conf. '02, (in Japanese), F141 (2002), pp. 271-272.

(20) Matsumoto, H., Electronic Parts and Materials (Densi-Zairyou), (in Japanese), Vol. 41, No. 7 (2002), pp. 29-34.

(21) Hebb, J.P. and Jensen, K.F., The Effect of Surface Roughness on the Radiative Properties of Patterned Silicon Wafers, IEEE, Trans. Semiconductor Manufacturing, Vol. 11, No. 4 (1998), pp. 607-614.

(22) CFD Research Co., http://www.cfdrc.com

(23) Nakayama, W., The Build-Up Approach to Combat Complexity and Uncertainties in Thermal Analysis of Compact Electronic Equipment, Proc. 6th ASME-JSME Thermal Eng. Joint Conf., TED-AJ03-566 (2003).

(24) Hirasawa, S., Maruyama, S. and Takeuchi, Y., A Rapid Calculation Method for Radiative Heat Transfer Analysis and Its Application to Lamp Heaters, Proc. 34th ASME National Heat Transfer Conf., NHTC2000-12266 (2000).

(25) Saito, T. and Satoh, I., Surface Profile Control for Thin Glass Plate by $\mathrm{CO}_{2}$ Laser, Proc. JSME Thermal Eng. Conf. '02, (in Japanese), D222 (2002), pp. 419-420.

(26) Grigoropoulos, C.P., Choi, T., Hwang, D. and Chimmalgi, A., Femtosecond Laser-Induced Materials Processing and Nanomachining, Proc. US-Japan Nanotherm Seminar, (2002), pp. 10-11.

(27) Kobayashi, Y., Fushinobu, K. and Okazaki, K., Fundamental Study of Opto-Thermal Wet Etching Technology, Proc. JSME Thermal Eng. Conf. '02, (in Japanese), D224 (2002), pp. 423-424.

(28) Silva, L.W. and Kaviany, M., Miniaturized Thermoelectric Cooler, Proc. ASME Int. Mech. Eng. Cong., IMECE2002-32437 (2002).

(29) Yabe, A., Nano-Technology and Heat Transfer, J. Heat Transfer Soc. Japan, (in Japanese), Vol. 41, No. 169 (2002), pp. 5-14. 